\title{
ORIGINAL RESEARCH
}

\section{"You'll be the RN soon": Separating performative roles of student and registered nurse}

\author{
Naomi Malouf ${ }^{* 1}$, Sandra West ${ }^{2}$ \\ ${ }^{1}$ School of Nursing, Queensland University of Technology, Queensland, Australia \\ ${ }^{2}$ Sydney Nursing School, University of Sydney, Sydney, Australia
}

Received: May 31, 2015

DOI: $10.5430 /$ jnep.v5n10p120
Accepted: July 17, 2015

Online Published: August 2, 2015

\begin{abstract}
Background: The transition to practice of (novice) Registered Nurses (RNs) is commonly seen as a simple process of "sliding" from one role to the other-Student Nurse (SN) to RN. How novice RNs accomplish moving from performing the role of SN to that of RN however, is rarely examined. Objective: To differentiate the performative roles of SNs and novice RNs.

Methods: Design: Interpretive qualitative design involving three sequential in-depth interviews during participants' first year of practice; Setting: Australian metropolitan acute care hospitals; Participants: Nine Australian novice RNs; Procedure: Emergent themes were identified using constant comparative analysis and further conceptualised through development of a series of diagrams to determine how elements of these transition experiences might interact.

Results: SNs rarely see the reality of performing as a novice RN until the role is actually upon them. While inextricably linked, these performances have become conflated into a conceptual continuum preventing acknowledgement of what are two distinct roles. Irving Goffman's dramaturgical work was used to develop emergent understandings of how both SN and RN roles were each distinctly rehearsed and performed. Margaret Archer's "inner conversation" was then used to develop an understanding of how novice RNs move between these roles.

Conclusions: Rather than assuming that SNs will adapt seamlessly to practice as novice RNs, attention needs to be given to differentiating the start and endpoints of this significant transition. Doing so will provide clarity around what educators expect of both roles and help those engaged in this transition to practice to celebrate their successes as both SNs and novice RNs.
\end{abstract}

Key Words: New graduate nurse, Registered nurse, Student nurse, Performance, Transition, Clinical education

\section{INTRODUCTION}

Globally, preparation-for-practice nurse education now largely resides in the higher education sector. By completing the Bachelor of Nursing degree (or equivalent), novice Registered Nurses (RNs) have achieved beginning clinical competence and met regulatory body requirements before joining the workforce. ${ }^{[1]}$ While there is almost universal recognition that novice RNs require a period of adjustment to enhance and develop skills within acute care settings ${ }^{[2-4]}$ there is often a corresponding organisational expectation that such novice RNs will be able to "hit the ground running" and effectively assess and manage complex patient needs. ${ }^{[5]}$ This however, is an expectation that novice RNs may not be ready to meet. ${ }^{[6]}$

There is a large educational literature addressing preparationfor-practice nursing degrees ${ }^{[7]}$ and an increasing literature, driven by workplace efforts to address retention issues, describing the needs and deficits of new RNs. ${ }^{[8-10]}$ This literature predominately focuses on the RNs within workplace movement from novice $\mathrm{RN}$ to more experienced (competent)

*Correspondence: Naomi Malouf; Email: naomi.malouf@qut.edu.au; Address: Victoria Park Rd, Kelvin Grove, QLD, 4059, Australia. 
RN and frames it as a "transition": a state that is understood to be descriptive of a relatively simple or perhaps evolutionary change from one form of nurse to another.

Currently, no studies that investigate how the move from performing as Student Nurse (SN) to performance as novice RN is accomplished have been located, suggesting that such conceptualisations have possibly remained unproblematically and implicitly framed by educators' knowledge of the apprenticeship model, rather than being reframed through specific problematisation to align with the current tertiary-based preparation-for-practice programmes. ${ }^{[11]}$ What is needed therefore are understanding(s) of the perspectives of novice RNs as they transition from SN to RN. While others have thought to use the concept of performance as it applies to work, very little literature exploring how nurses "perform" their work within the health care environment, or address how SNs initiate their performance as novice RNs. To address this gap Goffman's ${ }^{[12]}$ theorisation of performance in everyday life and Archer' ${ }^{[13]}$ work on the significance of the inner dialogue have been used to develop understanding of these distinct but also overlapping performances.

The broad aim of the major study was to explore the transition experiences of novice RNs by asking the question: How do individual new nurses experience their first year of practice as a registered nurse? Drawing upon a major theme of the study ${ }^{[14]}$ this paper looks to illuminate how the move from performing the role of $\mathrm{SN}$ to that of $\mathrm{RN}$ is accomplished.

\section{METHOD}

The goal of this interpretive qualitative study was to make sense of, or interpret phenomena in terms of the meanings that people bring to them. ${ }^{[15]}$ The longitudinal nature of the phenomena here (the new nurse experience) precluded the use of a formal Grounded Theory research design however analysis was conducted using the broad tenets of Glaserian Grounded Theory. ${ }^{[16]}$

\subsection{Sampling and recruitment}

Nine participants were recruited using a snowball sampling technique ${ }^{[17]}$ and were initiated by advertising in clinical areas and a university-based school of nursing. All participants were first year RNs employed full time in acute care tertiary hospitals in Sydney, Australia and who had completed their Bachelor of Nursing (BN) degree within 12 months of the study's commencement. Descriptive participant details are provided in Table 1.

\subsection{Ethical considerations}

Approval from university and hospital ethics committees was obtained. Participant confidentiality was maintained by al- locating randomly selected pseudonyms at initial interview. Participants were assured that their involvement in the study would not affect their employment or practice as registered nurses.

\subsection{Data collection}

A series of three, in-depth conversational interviews were used to capture changes in the participant's attitudes towards transition as they progressed through their first year of practice. This approach to data collection was selected so as to give "voice"[18] to the unspoken experiences of novice RNs. The interviews occurred at the approximate beginning, middle and end of their first year. Interviews, ranging from 45-90 minutes, were recorded and transcribed verbatim to maximise the credibility and trustworthiness of the study.

\subsection{Data analysis}

All data were managed using NVIVO8 software and consistent with constant comparative analysis processes data collection, analysis and interpretation occurred concurrently. In keeping with Grounded Theory methods ${ }^{[16]}$ data were subjected to initial line-by-line substantive coding, then focused selective and finally theoretical coding ${ }^{[19]}$ to identify themes. These themes and their interactions were identified and further conceptualised by a series of diagrams illustrating how elements of these transition experiences might interact. Conceptualisation was theoretically enhanced through sensitivity to the works of Goffman ${ }^{[12]}$ and Archer ${ }^{[13]}$ which broadened understanding of key elements of the analysis. These insights are the focus of this paper. ${ }^{[14]}$

\subsection{Theoretical framework}

Goffman's ${ }^{[12]}$ "The presentation of self in everyday life" examines how process and meaning in mundane interactions, present themselves in the "regular" lives of people. Using a symbolic interactionist framework, Goffman ${ }^{[12]}$ considered details of individual identity, group relations and the impact of environment on how people present themselves in social situations. He also examines the movement and interactive meaning of information to consider how the individual in “... ordinary work situations presents himself and his [sic] activity to others, the ways in which he [sic] guides and controls the impression they form of him, and the kinds of things he [sic] may and may not do while sustaining his performance before them". ${ }^{[12]}$ Goffman's perspective provides significant insight into the nature of social interaction and the psychology of the individual and is thus applicable to current working environments. Goffman's ${ }^{[12]}$ theorisation of performance in everyday life was used here in interpreting the findings to support differentiation of the performative roles of $\mathrm{SN}$ and novice $\mathrm{RN}$. 
Table 1. Descriptive participant details

\begin{tabular}{|c|c|c|c|c|}
\hline Pseudonym & Gender & Age & Previous experience & $\begin{array}{l}\text { Rotations and areas of clinical experience of } \\
\text { new nurse transition program }\end{array}$ \\
\hline Jamica & Female & 22 & AIN /Private Hospital & $\begin{array}{ll}- & \text { Cardiology } \\
- & \text { Respiratory } \\
\text { - } & \text { Emergency }\end{array}$ \\
\hline Blake & Male & 26 & Nil & $\begin{array}{ll}\text { - } & \text { Neurology/oncology } \\
\text { - } & \text { High dependency surgical } \\
\text { - } & \text { Chemotherapy } \\
\text { - } & \text { Maternity } \\
\text { - } & \text { Anaethetics/recovery } \\
\text { - } & \text { Day surgery/OT } \\
\text { - } & \text { Cardiac catheter laboratory } \\
\text { - } & \text { Cardiovascular } \\
\text { - } & \text { ICU }\end{array}$ \\
\hline Vanessa & Female & 24 & AIN/ Nursing Home & $\begin{array}{ll}\text { - } & \text { Orthopaedics } \\
\text { - } & \text { Geriatrics } \\
\text { - } & \text { Cardiology }\end{array}$ \\
\hline Suzanne & Female & 46 & AIN/ Private Hospital & $\begin{array}{ll}\text { - } & \text { Surgical ward } \\
\text { - } & \text { OT } \\
\text { - } & \text { Palliative care }\end{array}$ \\
\hline Carole & Female & 26 & AIN/Private Hospital & $\begin{array}{ll}\text { - } & \text { Surgical ward } \\
\text { - } & \text { Day surgery } \\
\text { - } & \text { OT } \\
\text { - } & \text { Anaesthetics/recovery } \\
\text { - } & \text { Neurology } \\
\text { - } & \text { Cardiovascular } \\
\text { - } & \text { Cardiac catheter laboratory } \\
\text { - } & \text { Maternity } \\
\text { - } & \text { ICU }\end{array}$ \\
\hline Katrina & Female & 28 & EN/ Public Hospital & $\begin{array}{ll}\text { - } & \text { Cardiovascular } \\
\text { - } & \text { Cardiac catheter laboratory } \\
\text { - } & \text { ICU } \\
\text { - } & \text { OT }\end{array}$ \\
\hline Natalie & Female & 26 & Nil & $\begin{array}{ll}\text { - } & \text { Surgical ward } \\
\text { - } & \text { Cardiothoraccic ICU } \\
\text { - } & \text { Respiratory }\end{array}$ \\
\hline Kate & Female & 26 & Nil & $\begin{array}{ll}\text { - } & \text { Cardiothoraccic ICU } \\
\text { - } & \text { ICU } \\
\text { - } & \text { Neurology }\end{array}$ \\
\hline Amanda & Female & 25 & Nil & $\begin{array}{ll}\text { - } & \text { Geriatrics } \\
\text { - } & \text { Haemodialysis } \\
\text { - } & \text { Cardiothoraccic ICU } \\
\text { - } & \text { Rehabilitation }\end{array}$ \\
\hline
\end{tabular}

Note. AIN: Assistant in Nursing; EN: Enrolled Nursing-Certified following 12 months training within the TAFE system.

Using a "dramaturgical approach" and structuring his argument around the metaphor of stage performance, Goffman ${ }^{[12]}$ asserts that the stage performer presents things that are imagined by presenting him/herself to another "actor" in the guise of specific, but fictitious characters. He sees interactions between people as "performances" that are shaped by the environment and audience, and constructed to provide others with "impressions" that are aligned with the desired goals of the "actor" ${ }^{[12]}$ The performance therefore exists regardless of the intent of the "actor", as the necessary persona is often accredited to the "actor" in spite of his/her lack of faith, belief, active involvement in - or even ignorance of - the 
performance process.

Similarly, Goffman's concept of "front" - which is closely related to the process of establishing a social identity - is described as “... that part of the individual's performance which regularly functions in a general and fixed fashion to define the situation for those who observe the performance". [12] This positioning allows others to come to know or understand an individual as a result of projected traits that have roughly standardised, and collectively defined meanings. As a "collective representation" the front establishes three properties for the social role as portrayed by the actor: the "setting" (the physical and emotional environment in which the actor acts); the "appearance" (the act of telling the audience of the social status of the individual); and the "manner" (acting as a warning to the audience of the role that one might expect the individual to play in the coming situation). The establishment and maintenance of this front unites the actors' inner landscapes with their external performance or personal front. ${ }^{[12]}$ The presentation of this unified front requires the actor ". . . to both fill the duties of the social role and communicate the activities and characteristics of the role to other people in a consistent manner": [20] An aspect of performance not commonly addressed in relation to SNs rehearsal of the role of novice RNs.

While Goffman talks of the larger concept of performance, individuals need to rehearse/process their performative roles in order to give a convincing performance. It was Archer ${ }^{[13]}$ who assisted us in developing an understanding of how this is accomplished and eventually incorporated into the being of the RN: the point where the personal transition to becominga-RN and actually being-a-RN combine.

In her discussion of the complexities of "Being Human", Archer ${ }^{[13]}$ identified the significance of the inner dialogue for managing emotions that emerge out of situations that confront us. She maintains that humans are continually, privately reflecting upon their circumstances, particularly in relation to their perceived social standing and sense of self and self-worth. We argue that this constant private reflection/inner conversation/dialogue facilitates novice RNs' in developing their performance from the initially guided, scrutinised performance of a student to the relatively independent performance of a novice then competent RN.

$\operatorname{Archer}^{[13]}$ asserts that certain fundamental characteristics of our personal, structural and cultural makeup, such as our emotions, are irreducible in that they cannot be conflated any further than their current state. As our emotions are one of the core components of our inner lives and an essential component of how we interact with the world around us, the crucial supposition is that our emotions matter because they are "... the fuel of our internal conversations".[13] One of Archer's ${ }^{[13]}$ central aims is to show "... how irreducible properties of our human selves interact with our sociality and that their interplay is significant by virtue of the inner dialogue and its outcomes". ${ }^{[13]}$ Archer also maintains that "... we are in a constant communion with ourselves and ... we engage in a continual running commentary about the events going on around us". ${ }^{[13]}$ This conversation is thus the full and expressive reflection of one's experience of being-in-the-world and it is this that facilitates movement toward a response. Such conversations underpin human agency and, as Archer says, "... the commentary is interwoven with our responses themselves: they are a part of the action".[13] Analytically attending to Archer's commentary resulted in a full-bodied, rich description of how these novice RNs experienced their transition to practice.

\section{Findings/RESULTS}

Because sometimes [as a student] you're just quite happy to cruise along... it doesn't really feel as though it's real until you actually do a big placement and then you go "Oh, OK. I don't actually know that". When your answer is still "Oh, I'll just go and ask the registered nurse"... you realise yourself without having to be told that it's very important that you know what you're doing. Because it will be you very shortly. You'll be the registered nurse (Blake 2:442)

However educationally appropriate clinical placements may be as a rehearsal for the role of $\mathrm{RN}$ as Blake explains here, it seems that SNs have difficulty seeing the reality of performing as a novice $\mathrm{RN}$ until it is upon them.

\section{Finding 1 - Performing as a novice RN: A continuum}

At graduation SNs have successfully completed their education as pre-registration students. Permission to perform the role of RN, however, begins at the point of registration and is necessarily accompanied by a corresponding level of clinical responsibility that it is not possible or desirable for SNs to assume during their education/rehearsal period. This shift in status from SN to RN (an accountable practitioner) is functionally as swift as a change from one day to the next, requiring only the payment of registration fees and evidence of successful completion of a tertiary qualification recognised by the regulatory authority. Upon beginning work, novice RNs are required to perform as RNs irrespective of their readiness or willingness to engage with the responsibilities of their new role. ${ }^{[21]}$ 
While SNs may to some extent have remained unaware of the full complexity and ramifications of practice as a $\mathrm{RN}$, once employed they are required to enact, in the presence of others, what Goffman ${ }^{[12]}$ describes as dramatic realization: the "... activity of infusing his [sic] activity with signs which dramatically highlight and portray confirmatory facts that might otherwise remain unapparent or obscure". Similarly, in order to maintain a coherent front, novice RNs need to clearly demonstrate proficiency in the tasks of nursing, concern about which can occupy a vast amount of novice nurses' thought processes as Amanda describes:

... the first thing... I am worried about is the skills because if I am looking after the patient and there's a lot of tasks involved, you have to have the skill to be able to look after them properly. Without the skills I can't look after the patient at all. That's why they put me there. That's what I get paid for. So of course, that is my primary concern - skills ... Of course when you go to a new ward you are worried about whether you can do it or not. Whether I am competent or not to be able to look after this kind of patient. This kind of surgical patient or this type of dialysis patient. Mastery of the skills are the minimum requirement so then you can perform the tasks. (Amanda 3:263)

Some participants began to recognise that performing as a $\mathrm{RN}$ was much more complex than they had understood when a SN when in addition to becoming familiar with a new clinical environment a seemingly unending list of activities also required completion as Natalie relates:

I mean if you're getting really busy you tend to get really stressed out because not only you have the patient saying "Oh, this hurts" or "I need this" you have your TL [team leader] saying "Oh you know you had better pick it up and discharge that patient or take them away" and so sometimes you get stressed out cause all of these things pile up on you and you say "But I'm only one! I wish I had more hands but I don't!" (Natalie 3:102)

While some participants struggled with being able to complete all the tasks of nursing in the time available others quickly became more skilled at integrating patient-centred care into their busy days. They became less task-focused (SN performance) and more willing and able to extend thinking about their practice to incorporate recognition of the patient's perspective (RN performance), although of course they were no less busy:
If it's very busy and I have ten antibiotics to give all at four o'clock then I will just prepare all of the IVs for this patient and then go and say to the patient "Hey, when are you available? Are you going to have a shower now? Or if you are not having any other physio session I thought we might spend half an hour in the shower together because it is going to be a busy day. Is it OK? Is it a good time now?" (Amanda 3:354)

Others began to identify clinical priorities and organising themselves and their work on that basis, rather than simply responding to the tasks that needed attention. Recognising, as Kate recalled, that determining clinical priority enabled more appropriate negotiation of her work with specific patients across a complete shift and in context of overall demands within a ward/unit:

On your busy days it's still extremely hard to... get everything done... that they want you to do not necessarily things that need doing but I've found that communication is the biggest key in patient handling. Just being able to say "I don't know". That works. "I don't know. I will find out and I will come back when I have found out.... If I'm not back in an hour, buzz me. Please, I'm human. I've written it down. I will try but if I get side tracked, call me." And that's fine. I don't take offence to being called anymore! (Kate 3:350)

Consistent with Goffman's ${ }^{[12]}$ notion of "front", novice RNs settled into their new sense of social identity as a RN over a period of time. Their RN role, with the increased levels of responsibility and accountability, looks and feels considerably different to their previous role of $\mathrm{SN}$ and also to the RN role they had rehearsed. Thus, in contrast to even successful $\mathrm{SN}$ performances, performing as a novice $\mathrm{RN}$ requires being able to consider the overarching structure of the day as well as assuming full responsibility for patient management. In accomplishing this, participants became agents of their own professional development, moving themselves toward styles of nursing practice that may in time align with the performance of competent RNs.

\section{Finding 2 - Inner conversations: An intrinsic action}

Changing the focus of novice RNs from micromanagement of their skills to a personally located experiential understanding of what is required to effectively nurse acute care patients does not happen suddenly. Rather as a means of moving beyond the $\mathrm{SN}$ rehearsal of the $\mathrm{RN}$ role, this developmental pro- 
cess is one of self-awareness and self-discovery and involves each individual becoming aware of their inner landscape.

Participants frequently relied on their inner conversations to help them respond to the immediate situations in which they found themselves. Recollections of these inner dialogues indicated the extent to which they were challenged by their perceptions of what was required of them. These self-exchanges constituted dialectic between the specific demands of performing the role of $\mathrm{RN}$ and the way they were feeling about themselves as novice RNs. In this way, participants were able to interact with their environment as RNs rather than SNs because, as Archer claims, “... we remain active subjects in our own lives and do not become passive objects to which things happen". [13] These inner conversations helped to guide and develop participants' novice RN performances, steering them away from the more fragmented and skills-based RN performance they had rehearsed as SNs.

Participants' inner conversations were particularly important when they were initially concerned with issues of task completion and achievement recognition. The inner conversation then became a tool for managing anxiety associated with their growing awareness of the complexity of practice, their need to manage that complexity and a means of projecting themselves while performing the role of RN. Some participants found it useful to approach their nursing activities as a series of steps to be completed and their inner conversation provided a way of privately articulating the ordering of a seemingly endless series of tasks. Reflecting on their experiences, many participants recalled important self-exchanges of this type from the first days in a new ward/unit. For example:

I just thought "Start at your first guy. Go through. Do your meds. Look at what you've got to do for people. See what's got to be done for them". If someone turns up and says "Why isn't this patient ready?" say "It's my third day. Don't know what I'm doing. You'll have to wait". I actually thought that to myself. (Blake $3: 539)$

Although, as Archer notes, the inner dialogue is always a continuous running commentary and reflection of the world around us, it is "... only in sudden or urgent contexts that we are aware of a specific emotion" ${ }^{[13]}$ emerging from it. In times of stress or concern therefore, individuals tend to become more cognisant of their situation-specific emotions and also more aware of the relevant inner dialogue. Thus Blake's "at the time" awareness of his inner conversation enabled him to act to harness his sense of agency, rather than become immobilised by his anxiety. It is likely that at interview (six

Published by Sciedu Press months later) he remembered this particular commentary because of the considerable anxiety he was experiencing about his ability to successfully manage the complexity of the day ahead.

When faced with unfamiliar situations and the need to convince their "audience" of the performance of the role of $\mathrm{RN}$ that they were delivering (see Goffman's ${ }^{[12]}$ notion of dramatic realization), the inner dialogue also helped some participants justify their behaviour and reassure themselves they were performing appropriately. As Blake describes:

And I thought "Do things as well as you know them and you must be at least halfway" and then if something comes up you're not totally out of it..., I never even felt, you know, "Oh no! Oh no! Things are going horribly wrong!" ... If someone turns up and they're only going to [be] the registered nurse up from theatres... and I know all the people in there and if someone like those registered nurses comes up yelling at me it's going to be "Well, it's not done. You're going to have to wait." (Blake 3:529)

Other participants however, recalled how their inner conversation merely reflected their fear about their perceived knowledge deficits and ultimately the impact of their performance of the RN role on their patients, as Natalie demonstrates when she recalls trying to find the courage to ask questions of other staff:

You just got to know who to ask and don't be afraid to ask anybody, because what usually goes on [in your head] is just like "Oh god I don't want to ask anyone because I don't want to get into trouble, but if I don't ask someone, I will still be in trouble because it will be my fault that I didn't ask for help knowing that I didn't know what to do". So you've just got to be brave enough to admit that you didn't know. (Natalie 2:392)

Natalie is seen here using her inner conversation to assess the implications of her actions. The resulting realisation that she needed to be "brave" enough to admit she needed assistance with selected elements of her care - was facilitated by this inner dialogue and is reflective of Archer's ${ }^{[13]}$ contention that these inner conversations are integral to our being and our intimate interactions with the world around us.

Archer ${ }^{[13]}$ is however, not so naïve as to contend that our inner conversations are always "right". Rather she views them as acting as a reflection of our thoughts and feelings about 
current circumstances. Additionally, Archer ${ }^{[13]}$ maintains that as human beings, we may have several simultaneous and independent commentaries with ourselves, which involves elevating some commentaries to a more important status and demoting others so we can consider their impact later This notion was repeatedly demonstrated in participants' descriptions of their inner conversations when determining what were "right" rather than "correct" concerns, as Suzanne demonstrates when considering how to prioritise her workload:

I got frustrated because you get so much work loaded onto you and then on top of that there's patients and relatives bugging you, you just want to tell them off but when I'm here I'm thinking, "Here they are in pain, that's why they are here"... But when I am here I know that pain management is the most important thing. (Suzanne 3:192)

These dialogues which participants engaged in as humans operating within a specific context (novice $\mathrm{RN}$ ), were a way of guiding their practice and could be seen as a means of supporting and developing their new novice RN roles. Such an intimate understanding of what participants thought and felt during this turbulent time has not previously been uncovered

\section{Discussion}

During their undergraduate/preregistration education, SNs are required to comprehend a set of increasingly complex skills and conceptual frameworks. Tertiary institutions, using spiral curricula ${ }^{[22,23]}$ and/or mastery learning techniques $^{[24,25]}$ require SNs to learn the skills and knowledge needed to complete their theoretical studies and clinical placements. In clinical laboratories, students assume the appearance of RNs and regularly rehearse the skills of their work on each other, simulated patients and actual patients in the "live" clinical environment. Similarly, examinations and assignment writing constitute a written "performance" intended to demonstrate to the audience/examiner the actors'/SNs' understanding of the concept under scrutiny and their rehearsal of the role of the $\mathrm{RN}$.

The performance of the $\mathrm{SN}$ is also frequently assessed - during classroom/laboratory and clinical experience. ${ }^{[26]}$ Here the SN (the actor) needs to give a nurse academic/examiner (the audience) a convincing "performance" as a SN rehearsing the role of RN by convincingly and correctly completing tasks related to a list of essential skills defined by curricular/regulatory requirements. To do this the SN first dons a uniform designed to reflect a RN's uniform, which is ar- guably interpretable as a costume and conceptually related to Goffman's ${ }^{[12]}$ development of "front", specifically "appearance". Second, the SN has to demonstrate their ability to co-ordinate a series of micro-steps embedded within the defined tasks (see for example Higgins ${ }^{[27]}$ description of steps required for safe medication administration). Passing this "clinical" component of their course is clearly related to the SN's ability to give a "good performance" (and should be celebrated as such) but is also closely linked to Goffman's ${ }^{[12]}$ notion of manner.

While Goffman ${ }^{[12]}$ describes the need for "... consistency between appearance and manner", he acknowledges that this state is not always achieved particularly when "... appearance and manner may tend to contradict each other". [12] However, when the notion of consistency is applied to the assessment of SN performance the lack of conceptual consistency by the assessors of performance is highlighted when SNs are required to behave/perform as RNs when they have not yet achieved the right to perform this "higher status" role - the role they are currently rehearsing. During clinical placements for example, students will typically "work" alongside a RN performing some of the tasks of that RN. The RN is required to countersign the SNs' work to confirm that the significant tasks of practice have been correctly completed. SNs are therefore rehearsing the role of RNs by undertaking specified tasks, but responsibility for their performance/rehearsal remains with the supervising RN.

The lack of a rehearsal framing within clinical contexts and the constant attention given to the higher status role of RN means that SNs are often viewed in terms of their ability to act as if they are novice RNs, rather than their ability to rehearse that role. Consequently, in assessable scenarios SNs need to convince assessors of the close fit between their performance and the audience/assessors' expectations of RNs rather than of SNs rehearsing RNs roles implicitly supporting Goffman's ${ }^{[12]}$ notion of learning as a "performance". The emphasis placed on performing rather than rehearsing the role of $\mathrm{RN}$ initiates the conflation of the $\mathrm{SN}$ and $\mathrm{RN}$ roles.

It is proposed that in the nursing profession's enthusiasm to facilitate the smooth transition of tertiary education graduates to the workforce, the distinction between the roles of SN and novice RN have become blurred. In previous apprenticeship models of preparation for practice, the only clearly evident distinction between a SN and a RN was often determined by legislative responsibility for tasks such as control of the scheduled medication keys. ${ }^{[28]}$ Today, while students are afforded the safety of not being totally responsible for the 
impact of the care they may provide in the clinical environment, SNs are often asked to "be" the RN, particularly when working with clinical scenarios and during their clinical experiences. In the absence of any empirical evidence, it is presumed that this practice occurs to give the SN a "taste" of being the RN as part of learning what it might be like to "be" the RN. While this modelling is logically sound, it places the $\mathrm{SN}$ in a precarious performative position. Which role are they being asked to perform and importantly for them, according to which role are they being assessed?

Successful completion of preparation-for-practice degrees means graduates are required by employing institutions to perform as responsible and accountable RNs, not - as they have become accustomed - supervised SNs who are rehearsing the role of RN. Current understandings of the SNs' transition to practice assume that satisfactory or exemplary $\mathrm{SN}$ performance will unproblematically translate into satisfactory or exemplary RN performance. We argue however, that recognition of the distinction between these two roles needs to be made both conceptually and practically more explicit. Doing so, may facilitate more effective celebration and recognition of their achievements as SNs who have rehearsed but not performed the role of RN and allow the confidence that such acknowledgement builds to provide a solid foundation for their development as novice RNs who are beginning their practice with the goal of becoming competent and eventually experienced RNs.

Previous work ${ }^{[21]}$ revealed novice RNs moving quite rapidly away from their SN-based rehearsal of the RN role toward performance of the novice RN role and the consequent acceptance of the increased levels of responsibility and accountability that are the hallmarks of the competent RN. We argue that as agents of their own professional development, understanding that performing the role of $\mathrm{RN}$ is different from $\mathrm{SN}$-based rehearsal of the $\mathrm{RN}$ role, is for some a beginning exploration of the mechanisms by which they may move themselves toward successful development of their performance as novice RNs.

\section{Conclusion}

The work of Goffman ${ }^{[12]}$ and Archer ${ }^{[13]}$ have been used here to support a distinction between rehearsing the role of RN while performing the role of a $\mathrm{SN}$ and performing the role of a novice RN. It is our assertion that there are therefore two distinct roles involved in the SNs' transition to practice as a RN. These roles need to be conceptually untangled to both enhance understandings of what it means to be a RN and also to acknowledge what it means to have successfully performed as a SN. Drawing upon Goffman, ${ }^{[12]}$ we suggest that student attention needs to be focused on successful performance as a $\mathrm{SN}$ while enrolled in preparation-for-practice nursing degrees. Rehearsal of the RN role is unquestionably occurring as SNs engage in the learning experiences required during this professionally determined period of education but this needs to be understood as a rehearsal and not a final performance. By not acknowledging or attempting to minimise the important differences between rehearsing the role of $\mathrm{RN}$ while performing as a $\mathrm{SN}$ and performing the role of the novice $\mathrm{RN}$, an opportunity to determine context and content specific support of professional development of novice RNs has been overlooked in current health care.

A tension persists then, between allowing SNs to perform as SNs during their clinical placement experiences and assuming that because they have satisfactorily completed the requirements for registration that they will inevitably be ready to seamlessly transition and perform effectively as novice RNs. While the clinical experiences embedded within tertiary nursing curricular are a widely accepted way of giving SNs an understanding of what it may be like to enact the role of the RN, a clear distinction between rehearsing and performing this role must be acknowledged and supported by both tertiary institutions and acute care clinical environment. Doing so will provide clarity around what we as educators are expecting of each role and help those engaged in being novice RNs to celebrate their successes in the student role as well as embrace the challenges of becoming competent RNs.

\section{Conflicts of Interest Disclosure}

The authors declare that there is no conflict of interest.

\section{REFERENCES}

[1] Cleary M, Happell B. Promoting a sustainable mental health nursing workforce: An evaluation of a transition mental health nursing programme. International Journal of Mental Health Nursing. 2005; 14(2): 109-116. PMid:15896258 http://dx.doi.org/10.1111 /j.1440-0979.2005.00367.x

[2] El Haddad M, Moxham L, Broadbent M. Graduate registered nurse practice readiness in the Australian context: An issue worthy of dis- cussion. COLLEGIAN. 2013; 20(4): 233-238. http://dx.doi.o $\mathrm{rg} / 10.1016 / \mathrm{j}$. colegn.2012.09.003

[3] Horsburgh M. Graduate nurses' adjustment to initial employment: Natural field work. Journal of Advanced Nursing. 1989; 14(8): 610-617. PMid:2778198 http://dx.doi.org/10.1111/j.136 5-2648. 1989.tb01603.x

[4] Wolff AC, Pesut B, Regan S. New graduate nurse practice readiness: 
perspectives on the context shaping our understanding and expectations. Nurse Education Today. 2010; 30(2): 187-191. PMid:19699561 http://dx.doi.org/10.1016/j.nedt.2009.07.011

[5] Kenny A, et al. Mature age students access, entry and success in nurse education: An action research study. Contemporary Nurse: A Journal for the Australian Nursing Profession. 2011; 38(1/2): 106-118.

[6] Cubit KA, Ryan B. Tailoring a graduate nurse program to meet the needs of our next generation nurses. Nurse Education Today. 2011; 31(1): 65-71. PMid:20417996 http://dx.doi.org/10.1016/j .nedt . 2010.03 .017

[7] Wynaden D, et al. Are universities preparing nurses to meet the challenges posed by the Australian mental health care system? Australian and New Zealand Journal of Mental Health Nursing. 2000; 9(3): 138-146. PMid:11887257 http://dx.doi.org/10.1046/j.144 $0-0979.2000 .00175 . x$

[8] Cunich M, Whelan S. Nurse education and the retention of registered nurses in New South Wales. Economic Record. 2010; 86(274): 396-413. http://dx.doi.org/10.1111/j.1475-493 $2.2010 .00632 . \mathrm{x}$

[9] Dockery AM. Workforce experience and retention in nursing in Australia. Australian Bulletin of Labour. 2004; 30(2): 74-100.

[10] Holmås TH. Keeping nurses at work: A duration analysis. Health Economics. 2002; 11(6): 493-503. PMid:12203753 http://dx.d oi.org/10.1002/hec. 747

[11] Mallaber C, Turner P. Competency versus hours: An examination of a current dilemma in nurse education. Nurse Education Today. 2006; 26(2): 110-114. PMid:16188349 http://dx.doi.org/10.1016 /j.nedt.2005.08.002

[12] Goffman E. The presentation of self in everyday life. Edinburgh: University of Edinburgh, Social Sciences Research Centre; 1956 PMid:16589899

[13] Archer MS. Being human: The problem of agency. Cambridge, UK; New York: Cambridge University Press; 2000. http://dx.doi .o rg/10.1017/CB09780511488733

[14] Malouf N. The transition of new graduate nurses: From beginning practice to seamless practitioner, in Faculty of Nursing and Midwifery. University of Sydney: Sydney; 2010.
[15] Black N. Why we need qualitative research. Joural Epidemiology and Community Health. 1994; 48(5): 425-426. http://dx.doi.o $\mathrm{rg} / 10.1136 / \mathrm{jech} \cdot 48 \cdot 5 \cdot 425-\mathrm{a}$

[16] Glaser BG. Basics of grounded theory analysis. Mill Valley, California: Sociology Press; 1992.

[17] Morse JM. Sampling in grounded theory, in The SAGE Handbook of Qualitative Research, A. Bryant and K. Charmaz, Editors. SAGE: London; 2007.

[18] Dunniece U, Slevin E. Giving voice to the less articulated knowledge of palliative nursing: An interpretative study. International Journal of Palliative Nursing. 2002; 8(1): 13-20. PMid:11823745 http://dx.doi.org/10.12968/ijpn.2002.8.1.10230

[19] Glaser BG, Strauss AL. The discovery of grounded theory: Strategies for qualitative research. Chicago: Aldine Pub; 1967.

[20] Barnhart A. Erving Goffman: The presentation of self in everyday life. 2003. Available from: http://www. hewett.norfolk.sch.u $\mathrm{k} /$ curric/soc/symbol/goffman.htm

[21] Malouf N, West S. Fitting in: A pervasive new graduate nurse need. Nurse Education Today. 2011; 31(5): 488-493. PMid:21036429 http://dx.doi.org/10.1016/j.nedt.2010.10.002

[22] Flemming N, Mills C. Not another interventory, rather a catalyst for reflection. To Improve the Academy. 1992; 11(1): 137-144.

[23] Harden R, Stamper N. What is a spiral curriculum? Medical Teacher. 1999; 21(2): 141-143. PMid:21275727 http://dx.doi.org/10. 1080/01421599979752

[24] Adams JD, Spencer SA. People in transition. Training \& Development Journal. 1988; 42(10): 61.

[25] Bloom BS. ed. Mastery learning. Evaluation comment. Center for the Study of Evaluation of Instructional Programs: Los Angeles; 1968.

[26] Girot EA. Assessment of competence in clinical practice: A review of the literature. Nurse Education Today. 1993; 13(2): 83-90. http://dx.doi.org/10.1016/0260-6917(93)90023-U

[27] Higgins D. Principles of safe administration of medicines, in Medicines management: A guide for nurses, P. Jevon, et al. Editors., Wiley-Blackwell; 2010.

[28] Russell RL. From Nightingale to now: Nurse education in Australia. W.B. Saunders/Bailliere Tindall Australian nursing resources series. 1990. 